This item was submitted to Loughborough's Research Repository by the author.

Items in Figshare are protected by copyright, with all rights reserved, unless otherwise indicated.

\title{
Caring: building a 'psychological disposition' in pre-closing sequences in phone calls with a young adult with a learning disability
}

\section{PLEASE CITE THE PUBLISHED VERSION}

http://dx.doi.org/10.1348/014466608X369467

\section{PUBLISHER}

The British Psychological Society @ John Wiley \& Sons, Inc.

VERSION

AM (Accepted Manuscript)

\section{LICENCE}

CC BY-NC-ND 4.0

\section{REPOSITORY RECORD}

Patterson, Anne, and Jonathan Potter. 2019. "Caring: Building a 'psychological Disposition' in Pre-closing Sequences in Phone Calls with a Young Adult with a Learning Disability". figshare. https://hdl.handle.net/2134/9360. 
This item was submitted to Loughborough's Institutional Repository (https://dspace.lboro.ac.uk/) by the author and is made available under the following Creative Commons Licence conditions.

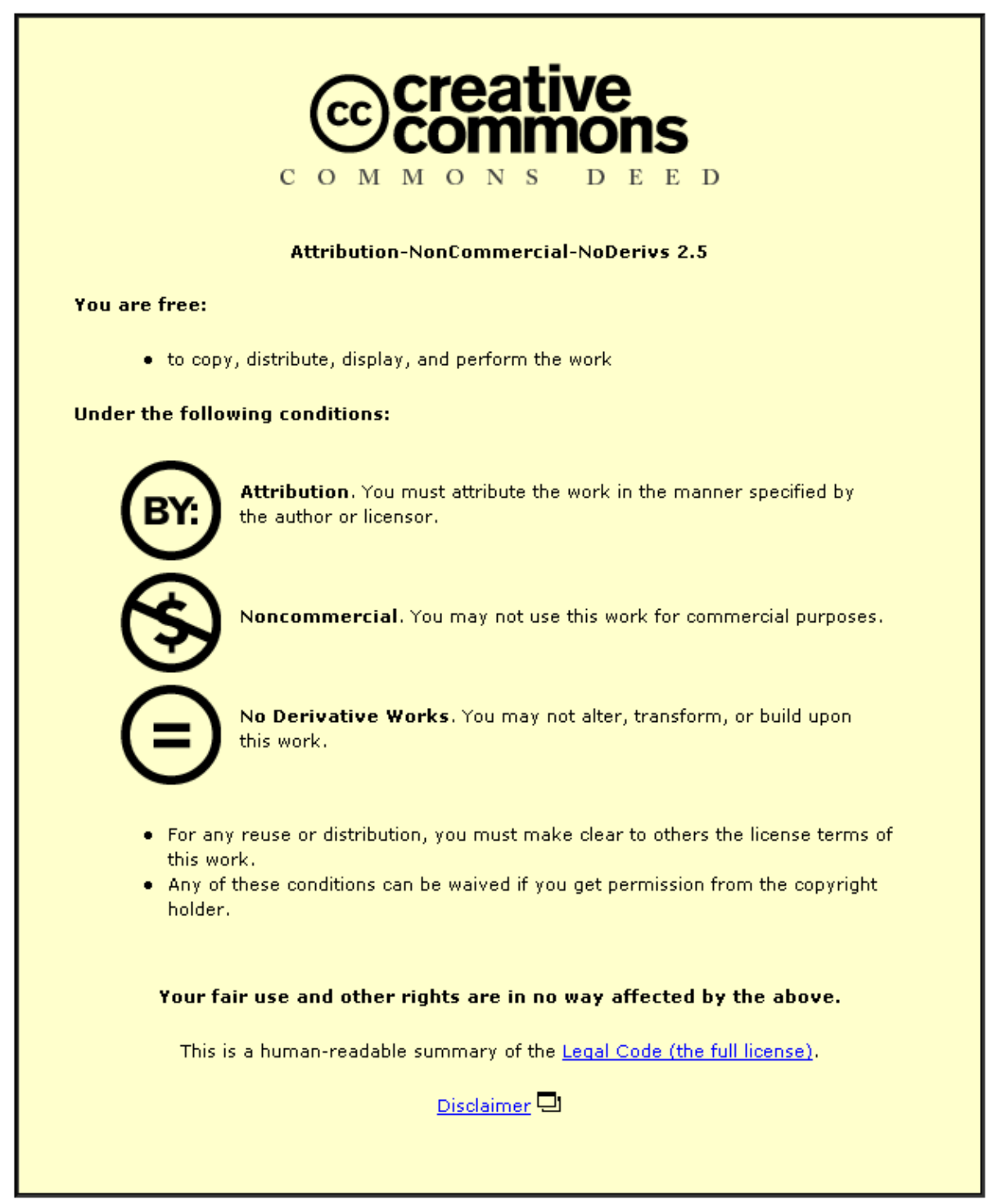

For the full text of this licence, please go to: http://creativecommons.org/licenses/by-nc-nd/2.5/ 


\section{Caring:}

\section{Building a 'psychological disposition' in pre-closing sequences in phone calls with a young adult with a learning disability}

\section{Anne Patterson \& Jonathan Potter}

Discourse and Rhetoric Group

Department of Social Sciences

Loughborough University

Loughborough

Leicestershire, LE11 3TU
Email: A.E.Patterson@lboro.ac.uk

Email: J.A.Potter@lboro.ac.uk

\section{To be published as:}

Patterson, A. \& Potter, J. (in press). Caring: Building a 'psychological disposition' in pre-closing sequences in phone calls with a young adult with a learning disability, British Journal of Social Psychology.

\section{Acknowledgements}

We would like to thank members of the Loughborough Discourse And Rhetoric Group, members of the audience at presentations at the International Conference on Conversation Analysis, Helsinki, May 2006 and the International Pragmatics Association, Gothenberg, July 2007 as well as Galina Bolden,for detailed and constructive comments on an earlier version of this paper. Flaws in the final version, of course, are our own. 


\title{
Caring:
}

Building a psychological disposition during pre-closing sequences in phone calls including a young adult with a learning disability

\begin{abstract}
This article has a joint focus on the way both psychological dispositions and matters of potential disability figure in interaction. The study works with a collection of more than fifty telephone calls between a young adult with a learning disability staying in a residential placement and three other members of her family. It focuses on the closing sections of the telephone calls and in particular how pre-closing turns may be designed to display caring. This paper analyses three formats through which pre-closings are delivered; through the use of announcements, interrogatives and imperatives. In each case the pre-closing commonly includes an account which provides a warrant for the impending termination. Detailed comparative study of the closing sequences in a corpus of mundane phone calls which do not include a disabled member finds very few such accounts. It is suggested that participants draw on accounts in a way that manages the potentially interactionally troubling matter of closing the call and, more specifically, to build the speakers' affiliative, 'caring', stance to one another. The analysis is used to consider broader issues about psychology and interaction, family relations and disability.
\end{abstract}




\section{INTRODUCTION}

Closing a conversation, and particularly closing a phone call, is a delicately organized matter. There are practical issues to do with the way closings are coordinated so that relevant matters can be dealt with before the termination happens. Conversation analysts have identified a robust set of organizational features that contribute to the orderly nature of closings (Schegloff \& Sacks, 1973). These practical matters are bound up with, and interactionally inseparable from, delicate psychological matters. One of the features of normative organizations such as the one that is found in the closings of phone calls is that departures from standard patterning can occasion psychological inference. For example, early termination might suggest boredom or disinterest; unwillingness to close might suggest loneliness or insensitivity. Sustaining or terminating conversation with another is a basic feature of sociality (Hopper, 1992).

In this paper we will use call closings as a kind of natural laboratory for considering the mix of practical and psychological matters that appear in a corpus of calls that took place between a young adult with a learning disability staying in a residential placement and three other members of her family. The interest will be on the way closing can be designed to ward off negative inferences and display an appropriately caring stance. In particular, we will focus on the way 'caring' can be understood as a practical, conversationally unfolding accomplishment with a range of systematic elements rather than a psychological disposition held by an individual. It is not that the individuals involved do not care (or, indeed, that they do care); it is that caring must be practically achieved in a way that makes it interactionally live. And call closings are an environment where caring becomes particularly relevant as issues of motive become potentially relevant. This move to consider caring as something 
public and interactional will go along with moving from an approach to 'disability' that considers it as a matter of individual (in)competence to an approach that considers the conversational procedures through which rich and equal communication can be interactionally sustained.

This approach to 'disability' has been developed in a most sustained programme by Charles Goodwin (2003a,b, 2004, 2006; see also, Antaki, et al. 2007a,b; Finlay, et al., 2008a,b; Ochs et al., 2004; Shakespeare, 1998). Goodwin's work looks in detail at the way speakers, including an aphasic man, use embodied resources, such as gesture, to complement verbal cues in conversations. His work illustrates the generous co-operation of co-participants (who put the extra time and effort into building satisfactory interaction) and the creative ways in which parties will work collaboratively to accomplish conversational tasks. Ochs et al. (2004) studied conversations which include children with Autistic Spectrum Disorder (ASD). Many children were observed to enjoy a great deal of success in conversational tasks, and in more complex interactions the reparation and scaffolding provided by others contributed to their success. Shakespeare (1998) too has looked at accomplishments in conversations that include people diagnosed as 'confused' speakers. Her work suggests that 'trouble' in talk can be seen to occur in normal talk as it does in confused talk and she too stresses the idea that all conversations are a joint venture and so are achieved through collaboration. While the participation of individuals with particular difficulties (aphasia, ASD, etc.) may mean that all parties to a conversation face special challenges, many of these are managed and overcome through the exploitation of generic conversational resources. In a related programme of work on interaction between residents and carers in a home for people with 'learning disabilities' Antaki, Finlay and 
others considered the way 'friendship', 'refusal' and 'choice' are managed and given psychological significance (Antaki, et al. 2007a,b; Finlay, et al., 2008a,b).

The current study will develop this tradition of work. It is part of a broader programme of work on mundane conversation which includes individuals with some kind of learning disability and considers how a rich and equal relationship is sustained in everyday talk. In common with contemporary discursive psychology (Edwards, 2005; Hepburn \& Wiggins, 2007; Wiggins \& Potter, 2008), and in contrast to the main traditions of both experimental and 'qualitative' psychology, the focus will be exclusively on naturally occurring interaction. Again, in common with contemporary discursive psychology the study will draw heavily on the methods and findings of conversation analysis (Sacks, 1992; Schegloff, 2006). This is part of a broader move to consider psychological matters as something practical and procedural rather than cognitive and individual. That is, it will follow the inspiration of Wittgenstein and Sacks rather than Fodor and Marr.

The analysis works with a collection of telephone calls between a young adult with a learning disability and other family members. Phone calls already offer an analytic focus that is more tractable than face to face settings as both parties (and therefore the analysts) only have audio access to each other's conversational actions. In this study, we have further restricted the focus by concentrating on call closings (or, to be precise, pre-closing sequences - not all pre-closings lead to actual call closings). The advantage of this topic is that closings are a clearly identifiable part of a call and make up a relatively constrained topic for which there is already a developed literature that can be used as a baseline. This made it possible to identify generic features of closings as well as any features that are unusual or unique to this corpus. 
As we will show in detail below, the parties display considerable conversational dexterity in the pre-closing turns to construct themselves as 'caring' (considerate, thoughtful, kind) toward the other and 'reluctant' to leave the call. We will consider some of the range of conversational resources that the parties draw on to build themselves as caring for the other and as reluctant to leave the call. The principal means for building caring we will discuss here is the use of accounts (typically formulations of external constraints of some kind that require call termination). We will focus on the design of these accounts, their sequential placement, and their collaborative production.

Accounts overwhelmingly occur as an element in one of three pre-closing formats: ${ }^{1}$

(1) those initiated by an announcement that the speaker has to terminate;

(2) those initiated by an interrogative about the wish/requirement of the other to terminate;

(3) those initiated by imperatives that direct the other to terminate. Note that there is a further potentially important difference between these designs. In design 1 the account is offered by the speaker initiating call closure for their own action of closing; in designs 2 and 3 the speaker initiating call closure issues an account for the recipient leaving the call. The latter two designs, then, allow us to consider the interesting situation where a speaker provides accounts for the activity of the other. Our analysis will consider these designs in turn. We will first overview our data corpus, introduce some generic and comparative material on pre-closings, and then use an example to illustrate the basic phenomena of interest. 


\section{DATA CORPUS}

The data corpus comprises of fifty two telephone calls between a young adult with a learning disability ${ }^{2}$ at a residential school and three other members of her family (her mother, father and grandmother). These calls are described as occasions for a 'casual chat' although as is the way of things various bits of family and organizational business get transacted in the calls. Their lengths ranged from 15 minutes to 40 minutes. We will refer to this as 'the APS corpus' ${ }^{3}$ Our analysis focuses on closing sections which are identified as being that part of the call from where a first reference to closing was made, either explicitly or implicitly, through to the terminal exchange which ends the call. We compared this corpus with a corpus of everyday casual phone calls the 'Holt' corpus to highlight features which concurred with or departed from the features in our closings. We have done further comparative work with a subset of the CTS corpus ${ }^{4}$ that features calls between mother and daughter and grandmother and granddaughter. All calls are transcribed using Gail Jefferson's transcription system that is standard in interaction research (Jefferson, 2004 see appendix).

\section{Architecture of a closing}

Let us start by sketching the standard pattern of closings that have been described in the conversation analytic literature. This will introduce basic terminology and help us highlight what is unusual or unique to our corpus. The following data fragment is from Button (1990: 132) and the terminology is provided by Schegloff and Sacks (1973) who initiated the study of telephone closings.

$\begin{array}{llll}1 & \text { A: } & \text { Oright } & \text { (passing turn loffer to close) } \\ 2 & \text { B: } & \text { Okay [ honey } & \text { (return passing turn/acceptance) }\end{array}$




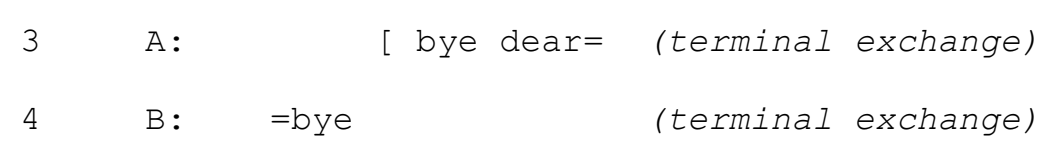

We can see that the standard closing has four parts, comprising two adjacency pairs. The first (lines 1 and 2) comprises an offer to close, known as a passing turn and an acceptance or return passing turn. A "pass" as defined by Schegloff and Sacks (1973) is an utterance that indicates that a participant has nothing else to add. It offers a free turn to the other should they wish to add anything. A "return pass" indicates that the second speaker has nothing to add either and so participants can move to terminal exchanges, which is the 2nd adjacency pair shown here in lines 3 and 4 . Alternatively the offer to close may be declined when, rather than a return pass, more topic talk takes place. Our focus is on pre-closing exchanges such as those in 1 and 2; the close initiating turn $(\mathrm{Cl})$ and the receipt of this that either accepts (A) or declines (D) the closing possibility.

The following example illustrates the form that pre-closings take in our corpus. We will use it initially to highlight their general architecture rather than specific content. Note the way there are recurrent attempts to initiate closing. It is common in the APS corpus for several instances of pre-closing activity to occur before closing takes place, and each offers the possibility of closing or of either returning to, or beginning topic-talk. Note that the closing comprises a (much) extended version of the archetypal closing form shown above. The main pre-closing sequences are shown in bold.

\section{Closing R210505}

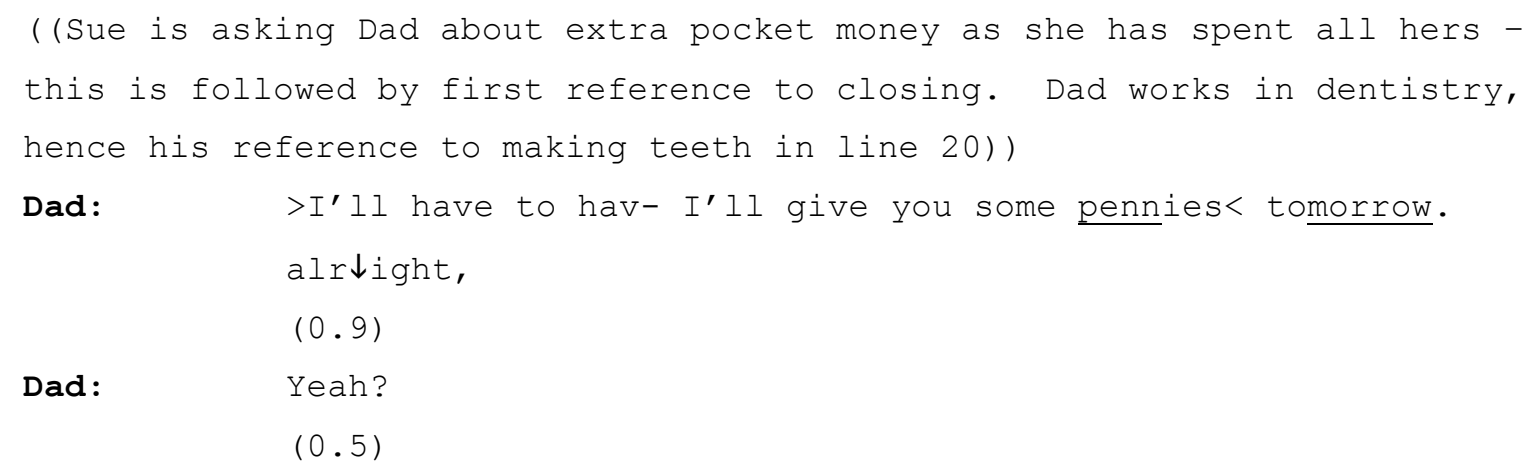


Sue :

Yeah.

Dad:

Okay.

(1.3)

Dad: $A \rightarrow$

Right >well I:'m gonna ged' on now<. I'll be there for about 'alf past nine, tomorrow morning.

Sue: Yea:h.

Dad: So ged up. an' get ready alright,

Sue:`Y Yea:h.

---Conversation continues for 45 turns---

Sue: $\quad$ Carrie $\downarrow_{\text {went }}$ with me

Dad: $\quad$ Good.

(4.5)

Dad: $B \rightarrow$ Right. >well I'm going to go now< darlin'. >cus I've got lots of< teeth to make.

Sue: Yea: :h I've got to finish ma cards off=

Dad: $\quad$ =okay >you finish yer card, $\quad I^{\prime} l l>$ finish ma teeth, $<$ and I'll >see you in the morning at 'alf. nine.< =we'll go an' av a nice $\downarrow$ day-out alright, $(0.5)$

Sue: $\quad A n w^{-\prime}$ all have a little wa:lk arou:nd, (.)

---Conversation continues for 5 turns---

Dad : [>she's gonna be in $a<$ wheel]ch>she's gonna be in a wheelchair.< so, (2.0)

Dad: C $\rightarrow \quad$ Oka:y,

Sue : Yeah

Dad: $\quad$ Alright darlin'

(0.9) 'ave a nice time, tonight. enjoy, the (.) \show.

Sue : $\quad \downarrow$ Yeah .

Dad: $\quad{ }^{A} A l r i g h t^{\circ}$ apparently there's some $\downarrow$ real ru:bbish on agen heh heh heh heh heh

Sue: $\quad$ Rubbish $\downarrow$ agen, 
Dad:

Some re:al funny ones yeah

Dad :

$$
\text { (1.2) }
$$

Yeah.

(2.0)

Dad: $\mathrm{D} \rightarrow$

Oka:y, lovey?

Sue:

(0.3)

Dad:

Yeah.=

Sue:

=I $\downarrow$ love you.

Dad:

Love you: , =

Sue:

=>Give me $a<\underline{\text { big kiss }}$

Dad:

((kissing noises))

Dad:

Sue:

((kissing noises)) \Mma: :h:

$(0.6)$

(2)

An $\downarrow I^{\prime} l 1$ see you >to[morrow mornin']<

---Conversation continues for 11 turns---

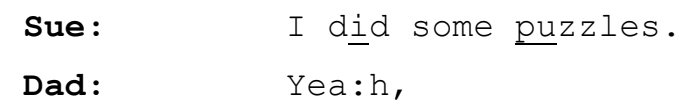

Dad:

Yea:h,

Daddy

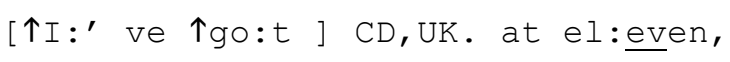

Dad: $\mathbf{E} \rightarrow$ $\uparrow R i g h t>I^{\prime} l l$ see you, < $\downarrow$ uhm >tomorrow: morning, $<$ (0.2)

Sue: Oka:y.

Dad: Alright, $\uparrow$ love: $y$ ?

Sue : okay

Dad: 个вy:e,

Sue : $\downarrow$ Bye .

Recycling of materials (e.g. on future plans in lines 10-11 and line 54 and 63) in more than one pre-closing is characteristic of closings in general (Schegloff \& Sacks, 1973; Button, 1987, 1990, 1991). Nevertheless, there are many more pre-closings in the APS corpus than the Holt corpus. For example, $78 \%$ of the Holt calls that involved casual chat has none or just one pre-closing episode before termination while all of the APS corpus has more than 
this.Indeed,, in the APS corpus $75 \%$ of calls has either three or four pre-closing episodes before termination.

The following table gives a precise breakdown of the numbers of pre-closing episodes.

\begin{tabular}{|c|c|c|}
\hline $\begin{array}{l}\text { Number }(\mathrm{N}) \text { of pre-closing } \\
\text { episodes prior to the } \\
\text { episode resulting in closing }\end{array}$ & $\begin{array}{l}\text { Holt Corpus - number of calls } \\
\text { containing }(\mathrm{N}) \text { episodes }\end{array}$ & $\begin{array}{l}\text { APS Corpus - number of } \\
\text { calls containing }(\mathrm{N}) \text { episodes }\end{array}$ \\
\hline 0 & 21 & 0 \\
\hline 1 & 11 & 0 \\
\hline 2 & 7 & 6 \\
\hline 3 & 1 & 21 \\
\hline 4 & 1 & 17 \\
\hline 5 & 0 & 2 \\
\hline 6 & 0 & 2 \\
\hline 7 & 0 & 2 \\
\hline 8 & 0 & 0 \\
\hline 9 & 0 & 1 \\
\hline TOTAL CALLS & 41 & 51 \\
\hline
\end{tabular}

(For the purpose of this comparison, monotopical 'professional/business' calls were excluded; these figures are for calls which had 'social business' as a main matter as these approximated most closely to those in the APS corpus).

Now compare the pre-closing activity in lines 10-11 (a pre-closing which is fairly typical of closings in general in that it includes an announcement to go and a reference to future plans), with that in lines 18-24. Note the way that the latter is significantly extended; it is more elaborate and also that it includes an account. It is the extended nature of these pre-closings and the inclusion of accounts that makes them unusual compared to the standard closings in the literature and our new analysis of closings in the Holt corpus. It 
seems clear that the talk is organised in order to take care of the business of closing in a particular way and the analysis below will attempt to explicate this.

Let us now look briefly at the structure of the pre-closing sequences (in bold). It can be seen that typically these sequences occur after a hearably long pause (lines 9, 18, 31, 44 and 62), at the possible end of a previously talked about topic and thus a possible place where a closing could be initiated. In all of the instances except the last, the pre-closing activity results in the proposal and take-up of further topic talk (lines 13, 26, 38 and 55). In lines 63-67 however, the pre-closing activity results in a move to terminal exchanges which take place in lines 68-69.

The pre-closing activity sometimes takes the form of a direct announcement as in lines 10, 19 and 63, but equally may be in the form of less direct, closing implicative utterances such as in lines $34-36,45,48,50,54$. In these latter cases the move to close is implied by:

- using a typical possible pre-closing form to offer closure as in line 45 ("Oka: $y$, lovey?") or the use of standardized closing-down-type material in line 50 ("> Give me $a<\underline{\text { big }} \underline{\text { kiss") }}$;

- the orientation to some future event as in lines 34-36 ("Alright darlin'. (0.9) 'ave a nice time, tonight. enjoy, the (.) $\downarrow$ show.") and line 54 ("An $\downarrow I^{\prime} l l$ see you >to[morrow mornin']<");

- $\quad$ the strong downward and thus conclusive-sounding intonational contour in line 48 (“I $\downarrow$ love you.") and In pre-closings $A, B$, and $E$ above, the possible move to close is initiated by an announcement to close and/or a restating of arrangements. In C and D a possible 
move to close is implied by use of tacit possible pre-closing turns which 'test the water' about a possible close. In $\mathrm{D}$ the move to close is also implied by a declaration of affection and requesting a kiss respectively, which are both gestures associated with goodbyes. These are conventionally recognised by parties to conversation as indicating that a closing may be live and imminent (Schegloff and Sacks, 1973). ${ }^{5}$ The general point of this illustration is to show that in the APS corpus:

- there may be several pre-closing episodes before the actual call termination;

- pre-closings may be explicitly delivered, e.g. by announcements;

- pre-closings may be indirectly implied by the use of closing implicative materials, e.g. by restating of plans,eclarations of affection or tacit possible pre-closings. Whilst the above observations are in line with standard closing conventions (Schegloff and Sacks, 1973), some features of closings in the current corpus are much less common in mundane call closings. One of the most notable of these is the use of accounts for closing. ${ }^{6}$ In raw distributional terms, $92 \%$ of the 52 calls in the APS corpus contain accounts as parts of pre-closings while only $7 \%$ of the 41 Holt calls reviewed contain accounts in pre-closings. There is a further distributional pattern that we will address later in this paper.

Overwhelmingly, certain of the pre-closing designs are used exclusively by the parent or grandparent caller. We will now consider the role of accounts in more detail. This will uncover potential explanations of this disparity.

\section{THE ROLE OF ACCOUNTS IN CLOSINGS}

In the following extracts the close initiating turns are marked (Cl) in order to highlight features of these closings that conform to the structural standards of Schegloff and 


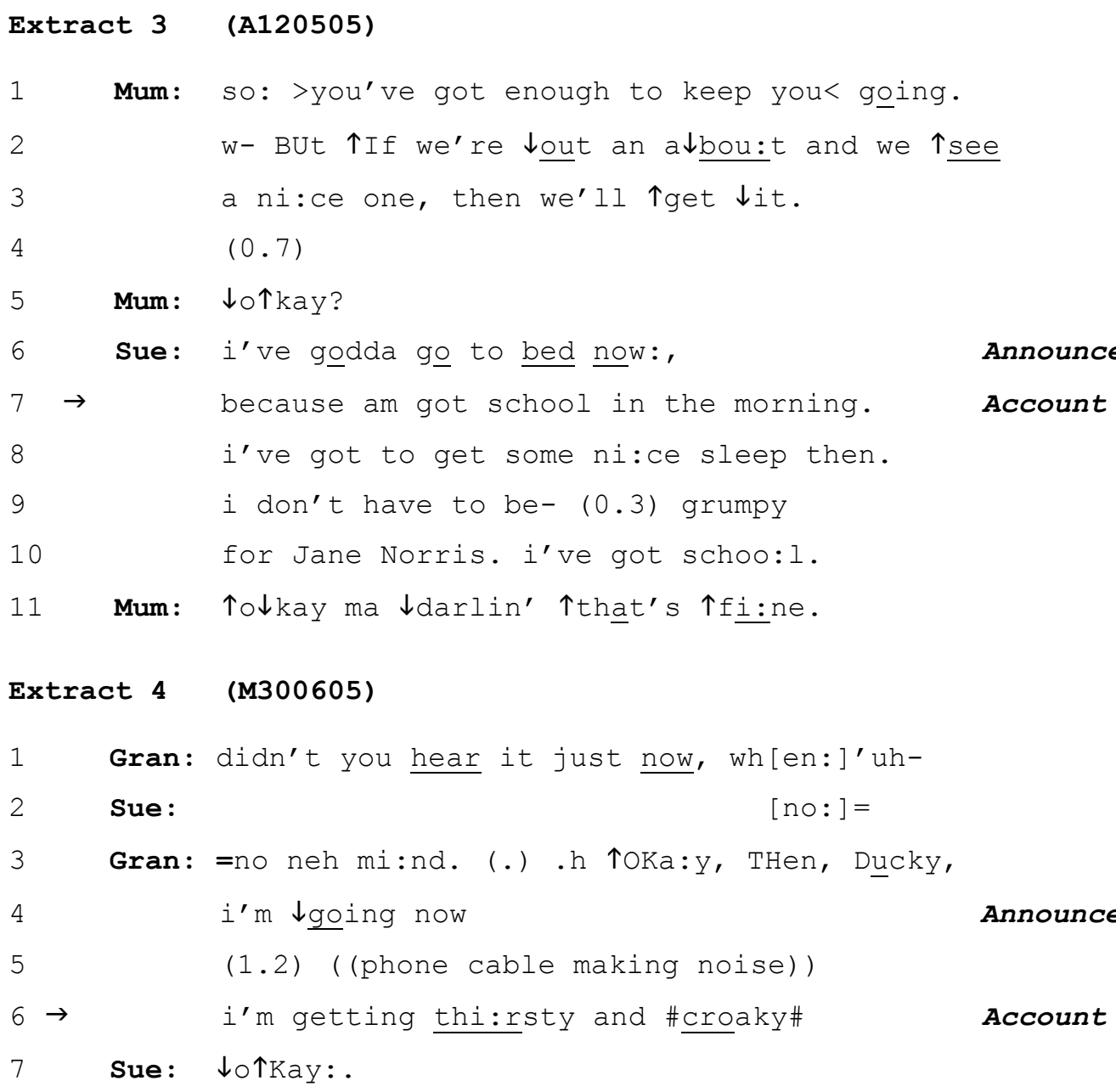

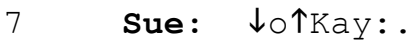

Account

In all four of the above extracts one participant announces an intention to 'go' (and thus close the call). These can be seen in Extract 1, line 5; Extract 2, line 6; Extract 3, line 6 and Extract 4, line 4. In each case the announcement is followed by an account in the same turn of talk.

Note the detailed design of the accounts. In Extract 1 both Dad and Sue specify tasks that they have to accomplish. The strength is marked by the 'got' constructions. In Extract 2 Mum's account is built with a softer requirement - although 'getting tea' is a duty to be done, it is something she 'supposes' and is 'thinking about'. Such an account may be designedly more open to the declined pass, which is what we see on line 8. In Extract 3 Sue also uses a 'got' construction, with an elaborate account for having to go to bed (to get 
quality sleep that will stop her being grumpy at school). In Extract 4 Gran's account emphasises her physical limitations. Each account is built from highly conventional resources that specify the constraining role of work, school, meal preparation, and bodily fatigue of one kind or another. What these widely different accounts have in common is that they make leaving the call a requirement and in this way the speaker reflexively produces him or herself as reluctant to do so. Accounts (combined with other lexical, grammatical, prosodic and sequential features that are discussed elsewhere - Author, in preparation) do delicate relationship sustaining work. They build each speaker's care for the other. Let us now consider the second of the three main pre-closing designs that use accounts.

\section{Interrogatives + accounts}

In a second pre-closing design accounts are used with questions. In the first of the examples the close initiating and responding turns are highlighted once more to illustrate the structural features of these pre-closings in relation to the archetypal closing; for clarity we will do this on just the one example.

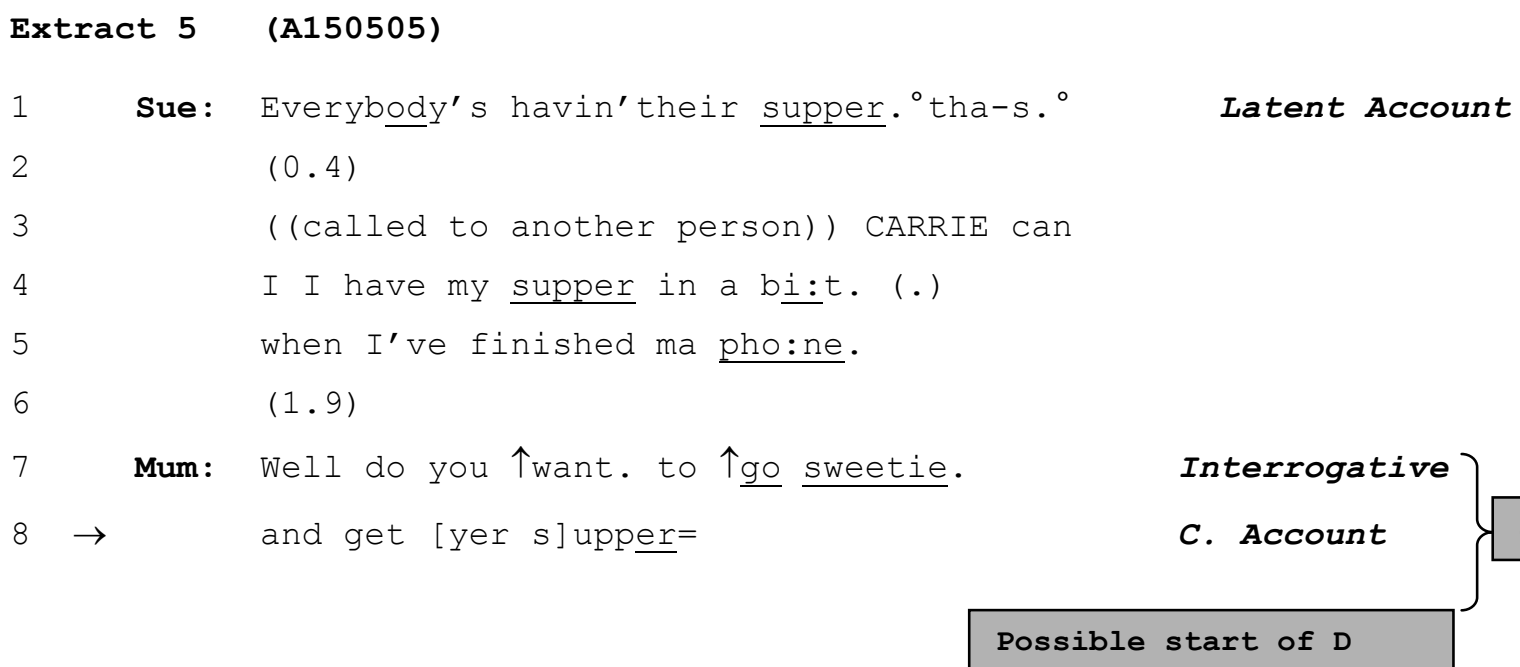




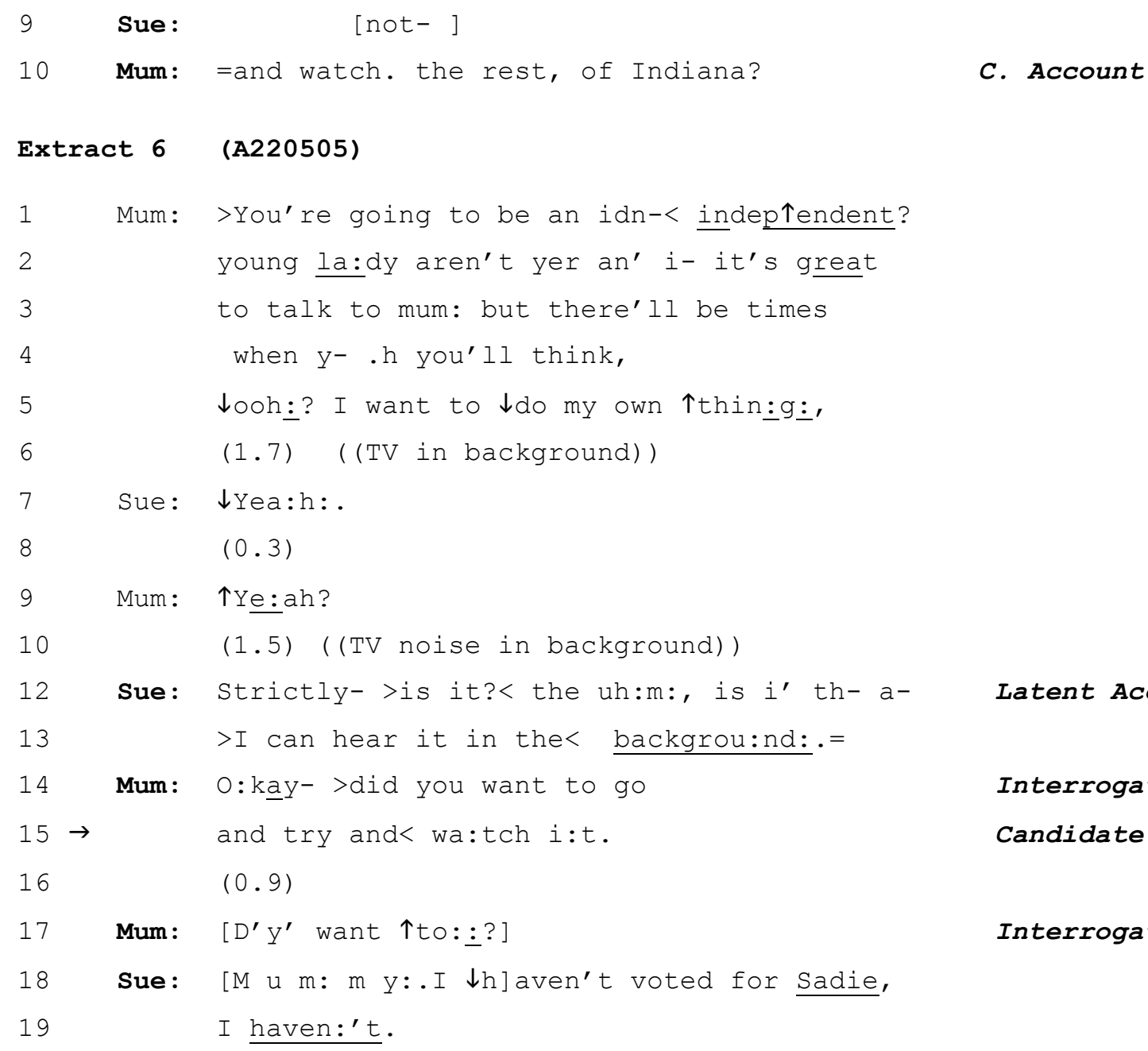

\section{Extract 7 (A200505)}

((Sue sounds sleepy throughout the whole call))

1 Sue: What ti:me is $\underline{i}$ t ? Latent Account

2 Mum: $\uparrow$ Uh:m: let's have a look.

$3(0.8)$

4 Mum: Mum: makes it about->it's about< quarter

5 past ni:ne ma lo:v:e.

$6 \quad(3.8)$

7 Mum: Are you wanting to go: $\downarrow$ ma $\downarrow$ darling,

Interrogative

$8 \quad(2.3)$

9 Mum: It's $\uparrow$ okay to say that you want to $\downarrow$ go $y^{\prime} \downarrow \underline{k n o w}$,

$10 \quad(2.9)$

11 Mum: $\downarrow^{\prime} l l$ talk to you for as $\uparrow l o: n g$ >as you li:ke,

$12 \rightarrow \quad<$ but if you- (.) feeling rather ti:red,

Candidate Account

13 and you want to go an get comfy, and watch telly,

14 (0.6) you've just gotta $\downarrow_{\text {sa:y }}$. 
What is different about these kinds of accounts is that the speaker who initiates the closing is providing an account for some action that the other will need to perform. In this case, the interrogative form offers to close building the account as the other's requirement to go. Typically materials appear in the call that could be used to account for closing, but have not yet been formulated in this way. We refer to these as latent accounts to reflect their yet to be formulated as such status. They are built as an interrogative that offers a candidate account for leaving the call. Thus in Extract 5 Sue appears to be fending off a request from a party outside the call for her to go to supper. Mum follows this with an interrogative form that asks Sue if she wants to leave the call to get supper and watch the rest of an ongoing movie.

In psychological terms this transacts a complex piece of relational business. One party is building a candidate account for the other party to leave the call. It displays care for the other's circumstances and constraints by acknowledging that they may be required or may want to leave the call and constructing this as acceptable. Indeed Mum in all three extracts attends to Sue's 'wants' and in Extract 7 overtly expresses that Sue's want is "^okay" ( line 9). Note that in doing this the speaker simultaneously presents him or herself as not wishing to leave the call, and as caring about the constraints on the other. ${ }^{7}$

We can see the same pattern in the next two extracts. In Extract 6 Sue reports hearing the sound of a favourite television programme (one much discussed elsewhere in the calls). Mum crystallizes the latent account into an explicit candidate by asking Sue if she would like to watch it. Across this corpus of calls the television schedule is repeatedly used in accounts for closing. One feature of such schedules is that they are a public resource 
available to all; and the start of programmes cannot be delayed for individuals.

Furthermore, using an interrogative form is particularly effective as it builds a display of caring for the other's interests and preferences. In Extract 7 Sue's interest in the time (combined with sleepy sounding delivery of talk) is drawn upon by Mum as a possible indication of tiredness. This is built into a candidate account that is offered to Sue.

In general, passing turns are designed to 'test the water'; to check participants' readiness to proceed to terminal exchanges. Questions are a particularly explicit form of checking. Pre-closings using questions, however, follow the same pattern as pre-closings using announcements to leave the call; the parties are both built as wanting to stay in the call, but required by timetables or pressures to leave the call (even if those pressures are themselves psychological ones such as pleasure missed by failing to see a favourite television programme). As with announcements, questions offer an extended version of the more minimal passing turn described in Schegloff and Sacks (1973). This extension includes (but is not restricted to) the account and the explicit checking.

\section{Imperatives + accounts}

A further group of pre-closings in the corpus use imperative forms. Schegloff and Sacks (1973) observed that imperatives provide a warrant to close the call; such warrants often use materials from earlier in the conversation. These pre-closings typically elaborately spell out what the other speaker should go and do, and this in turn is built as a desirable activity. Again this focuses on the needs or desires of the other speaker and in this way builds the closing as caring. These pre-closings are similar to the interrogative form. Material produced prior to the pre-closing can be viewed as a latent account; the speaker 
offers an imperative to close the call, fashioning a candidate account to justify the closing.

The close initiating turn and response have been marked on the first extract once more to show how these have structural features in common with the archetypal closing.

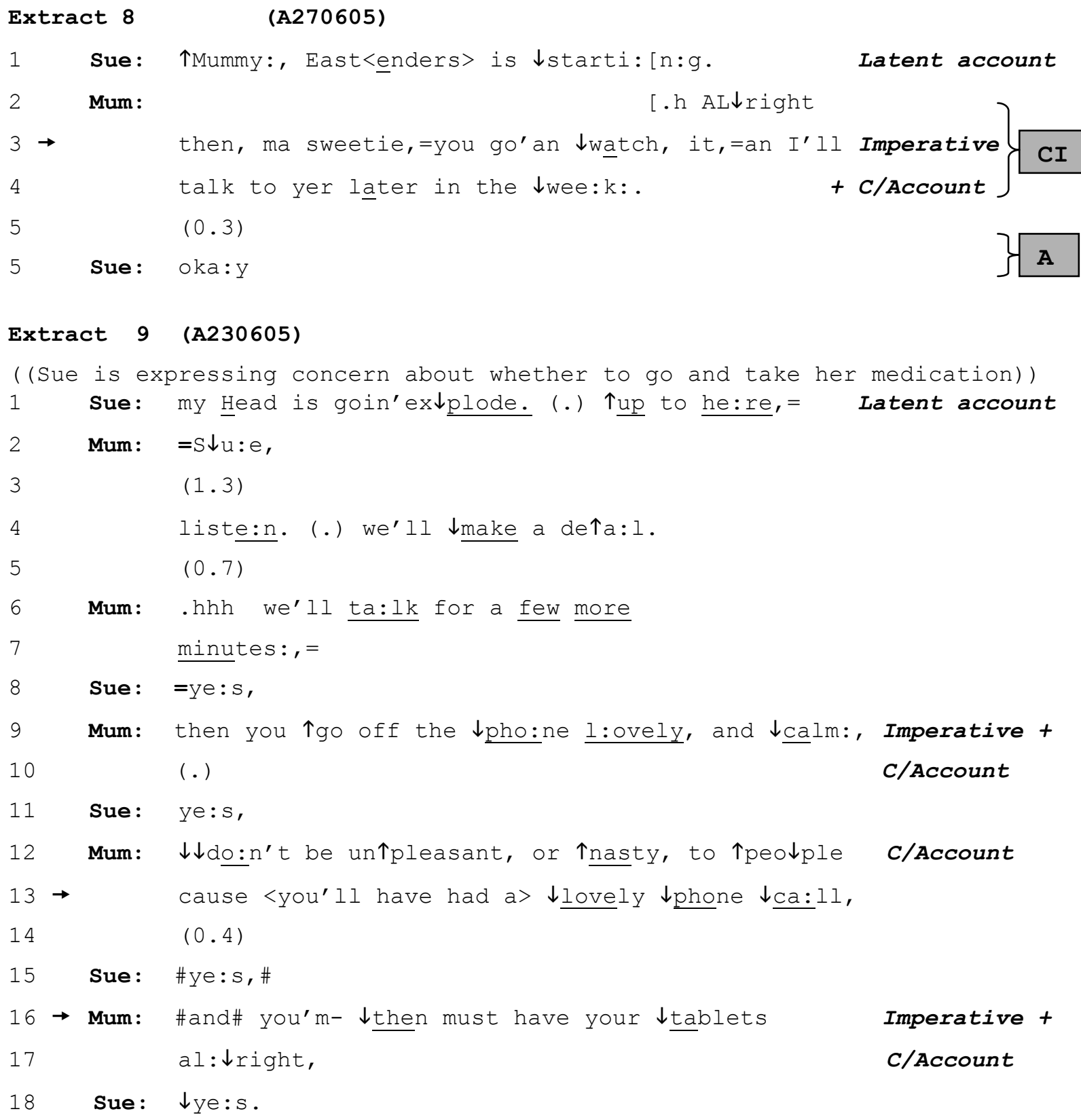

\section{Extract $10 \quad$ (A200505)}

1 Sue: >If I drop to sleep on this phone Latent account

$4 \quad$ Mum: $\downarrow_{W e}: 11$ I just think if you sit there 
In each of the above the extract starts with a mention of something that could require the ending of the call; these are what we have called latent accounts. None of this material is delivered as a passing turn. As with the interrogative examples, the recipient reformulates the material into a candidate account for closure. In Extract 8 Sue mentions a TV programme that is starting and Mum draws on this to form a passing turn that uses it as an account for closing, and this accompanies an imperative which directs Sue to go and watch it. Extract 9 takes a similar pattern, although here instead of the latent account being a liked television programme it is a reference to the effects of not taking medication. The directive in this extract is somewhat softened by making it part of 'a deal' (line 4). As Levinson (1983) has noted, imperatives are often used where something is being offered 'have a drink'. In Extract 8 the call closing is promising something positive - the enjoyment of a favourite program. In Extract 9, however, taking medication is positive only in the restricted sense it may relieve discomfort and produce calm. This may be the reason the directive is softened. 
In Extract 10 Sue refers to the possibility that she may fall asleep (line 1). This is only latent as an account as she does not offer it as a reason to close. In line 4 Mum adds to this commentary herself by saying that Sue may also get cold if she sits by the phone and falls asleep. And in line 7 Mum begins to build an account which is delivered using an imperative form prefaced by a phrase relating to Sue's "ineed" to do a mixture of positive things (comfortable chair, television, bed). Mum builds the account for Sue leaving the call here from a range of familiar generic resources supported by material from earlier in the call. Note that the elaboration here may be partly occasioned by the lack of uptake at 6,10 and 15. As with the previous designs, the imperative + account design builds closing as something required in some way rather than desired by the parties to the call.

\section{DISCUSSION: CARING CLOSING}

This analysis has considered the way closing is done in a corpus of calls that include a young adult with an identified learning disability. The patterning here is striking. The calls use standard patterns for opening up closing (passing and return passing turns). However, they (a) involve significantly more pre-closings than a comparative corpus of mundane calls and (b) they incorporate a range of additional elements. That is, closing here seems to involve more work than is seen in the mundane Holt corpus. In this analysis we have focused on the way closings are built with designs that announce, ask or direct call closure. Elsewhere we have considered a range of further elements that are common in closings in the APS corpus (including terms of endearment and intonational contours - Patterson, in preparation). We have been particularly interested in the way these designs are part of building the psychological dispositions of the parties. 
The announcement + account format is the simplest of the three. The speaker announces that they intend to close the call and provides an account for this. The account is built to produce the termination as something reluctantly done, something that the speaker does not desire. The call is produced in such a format as something that both parties would continue if it were not for the constraints detailed in the account. These constraints are typically highly conventional - work, school, meals (eating and preparing), and bodily fatigue of one kind or another.

The question + account format is more complex. One party asks the other if they wish to leave the call. In doing this, they offer the agency to the other for the closure of the call (the recipient can accept or decline - both are common). The question is accompanied by an account. In this case, however, the account is one formulated on behalf of the recipient. ${ }^{8}$ This is more psychologically complex - the account both formulates and attends to the interests and desires of the recipient. In so doing the speaker produces themselves as someone who understands those desires and has the right to formulate those desires. In so far as it attends to these desires and interests the closing is produced as caring. It is produced as in the service of the other. Note, however, that one feature of this format compared with announcement + account is that the speaker's own desires and interests are not treated as a relevant part of the closing; he or she does not have to attend to their own (possibly problematic) accountability.

The directive + account format is somewhat similar. Although the directive does gives more of a 'push' than the question, in this position it can be, and is, regularly resisted by the recipient opting to decline the option to close the call. Again the account is produced as in the service of the other, with the speaker producing themselves as knowing about, and 
concerned about, the interests of the other. It is therefore a format that displays caring (although again it also has the potentially notable effect of discounting the speaker's own accountability in the call closure).

\section{Caring and reluctance}

In this analysis we have highlighted the way 'caring' (for the other) and the closely related 'reluctance' (to close the call) are built interactionally. These psychological attributes become live in particular sequential environments. For example, pre-closings are an environment where the speakers' motivations may be at issue. Why is the speaker opening up a closing? Are they 'bored'? Do they 'dislike' the other party? This is a key environment for the attribution of psychological states. As we have seen, participants show a strong orientation to this both through the placement of accounts just where closing is raised as a potential next action, and through the form of the accounts. These accounts present either self or other as reluctant to leave the call. If it was not for the various constraints on the parent/grandparent, or their sensitivity to Sue's constraints, needs or pleasures, they would be continuing the call.

We can further refine this discussion by considering the difference between the Holt corpus and the APS corpus. We have noted that accounts are extremely rare in the Holt corpus and extremely common in the APS corpus. This suggests that pre-closing per se is not an accountable matter, otherwise we would expect to see the many more accounts in the Holt corpus. Two obvious candidates for what is distinctive are the parent/grandparent daughter relationships in the APS corpus and the (diagnosed) disability of one of the parties. This can be seen in two striking asymmetries. First, accounts are overwhelmingly produced 
by the parent or grandparent. Although we have given an example in the analytic section of Sue initiating an account in the context of an announcement, this is rare. More typically Sue announces she has to go without using an account or using materials that have already been worked up by her interlocutor. The second asymmetry is to do with the design of the accounts - only parents or grandparents produce accounts for Sue leaving the call. There are no examples of Sue producing an account for the other party to leave. Producing an account for the other is a delicate matter; there is a strong emphasis in interaction on speakers having primary rights to know and describe their own knowledge states, motives and beliefs (Pomerantz, 1980; Heritage and Raymond, 2005). This asymmetry is likely to be related to the special relational nature of these calls compared to the Holt calls.

There is a further feature of the design of accounts for the other. They construct reasons for going which focus on the needs and interests of the other party. In the examples above, we see accounts that focus on such things as favourite television programmes, eating, sleeping and taking medicine that will calm their mood. This adds a further element of caring. It is not just that pre-closing is treated as accountable, and that one party produces an account for the other, it is that the account is built as responsive to, and protective of, the needs and interests of the other. Neverthless, as we have noted above, although the account is built as responsive in this way this does not rule out its use in obscuring the grandparent/parents' interests or desires in closing the call.

\section{Collaboration, Asymmetry and Disability}

As we have indicated, the production of accounts for the other is massively produced by the parent or grandparent. Nevertheless, such accounts are built 
collaboratively in the sense that it is common for Sue to produce materials that could be a basis for leaving the call (we have called these latent accounts) and for the parent/grandparent to fashion these materials into a full account for closure. The effect here is a pre-closing produced as collaborative even though one party is doing much of the work. This is the kind of patterning that Goodwin (2003) observes in his work on aphasia and Ochs et al. (2004) observe in the context of autism. All of these cases indicate the importance of having a cooperative co-interlocutor or what Solomon (2004: 265) refers to as a 'generous interactional partner'. Much work too is carried out in recycling prior turns that may not have yielded a convincing affirmation from Sue of a possible move to closing initiation, and more turns and extra prompts are used to ensure that this is the wish of Sue. Note again that the three formats - announcement + account, question + account and imperative + account - constitute a considerable intrusion into the basic pattern of preclosings identified by Schegloff and Sacks (1973) and exemplified in the patterning in the Holt corpus. A key issue is precisely what motivates this intrusion into the minimal set of turns that are commonly sufficient to close a call. That one party to the talk has a diagnosed disability might have been seen to be a candidate, given that that was one of the distinctive criteria for building this corpus in the first place. However, what is going on is complex. What we see is an intrusion rather than an absence, and this intrusion appears to be directed at relational matters rather than being driven by issues of competence or impaired performance. Moreover, this corpus is different from the Holt corpus not just in having a party with a learning disability; that party is also living away from home and receiving calls from close family members. So the intrusion may be driven as much by relational matters than being a consequence of disability. An exploratory analysis of another corpus (the CTS 
corpus) supports this interpretation. The closings of five calls between a mother and daughter staying away from home and a call between grandmother and grandaughter were studied in detail. In every case pre-closings were accompanied by accounts.

There is also some cross cultural evidence that bears on this question. Bolden (2005, 2006) found that a range of discourse markers appeared in the pre-closings of Russian calls over and above the canonical Schegloff and Sacks (1973) pattern. It may be, however, that these calls are typically between parties with close and asymmetric familial relationships, suggesting that these may be relevant in addition to possible cultural differences. Pavlidou (2002) found that closings were considerably extended in the closings of Greek phone calls. Interestingly, however, she suggested that this was more likely to be a consequence of these calls being 'between friends and relatives' (2002: 225) and therefore doing specific relational business rather than being a consequence of Greek cultural issues per se. Pavlidou (2002) concludes that the canonical closing, whilst providing an economic route towards closing in an interactional sense, doesn't attend to the relational aspects in such talk.

More research will need to be done to clarify this issue. Nevertheless, we suggest that it is most likely that account intrusion in pre-closings is most common where there is some kind of close but asymmetric relationship such as between mother and daughter. The asymmetry may be heightened by one party being vulnerable (reluctantly away from home, say) or having some kind of disability. In this environment pre-closings may be particularly problematic for what they suggest about relational matters. This is managed by building accounts which display the closing as reluctant and attend to the desires and interests of the 
more vulnerable party. Caring is displayed in precisely the environment where it might be at issue.

Although we have suggested that the intrusion of accounts into the canonical closing may be more about fundamental relational matters than being a consequence of disability, the massive asymmetry in which party produces accounts and, in particular, the production of accounts for the other party seems more likely to reflect the different skills or authority of the parties. Sue does not build accounts for the other into question + account or imperative + account formats in pre-closings. Such designs are exclusively produced by parent or grandparent. More work will be needed to explore how far these formats are utilised by parties without learning disabilities when producing pre-closings in calls with parents or carers.

In general, we have highlighted the way 'caring' can be studied as a dynamically produced display, occasioned by a discrete interactional environment. Caring is built precisely where it is needed, where relational issues are brought into question by preparations to close a call. Caring is constructed through particular kinds of accounts that show reluctance to leave the call and attend to the desires and interests of the weaker or younger party. In a Wittgensteinian vein, we suggest that this is an ideal first place to look at caring because it is here that it is live, communicable and visible. What we have offered here, then, is one fragment of a broader discursive psychology of caring.

\section{Transcription}

The transcription system is standard for conversation analysis and related interactional studies. The principal notion is as follows: 
Square brackets mark the start and the end of overlapping speech.

$\uparrow \downarrow \quad$ Vertical arrows precede marked pitch movement.

Underlining Signals speaker's emphasis.

CAPITALS Mark speech that is obviously louder than surrounding speech.

I know it, ${ }^{\circ}$ Degree signs enclose obviously quieter speech.

(.8) Numbers in round brackets measure pauses longer than 0.2 seconds.

(.) A pause of 0.2 seconds or less.

((text)) Additional comments from the transcriber.

::: Colons show degrees of elongation of the prior sound; the more colons, the more elongation.

hhh Aspiration (out-breaths); proportionally as for colons.

.hhh Inspiration (in-breaths).

Ye:ah, Commas mark weak rising or 'continuing' intonation.

Ye:ah. Full stops mark falling or 'completing' intonation.

? Question marks signal questioning intonation, irrespective of grammar.

$>\quad$ Less than and greater than symbols enclose speech that is noticeably quicker than the surrounding talk.

$=\quad$ Equals signs mark the latching of one element of talk to another.

Fully detail on these symbols and their use is provided in Jefferson (2004). 


\section{References}

Antaki, C, Finlay, W.M.L., Jingree, T and Walton, C. (2007a). "The staff are your friends": conflicts between institutional discourse and practice, British Journal of Social Psychology, 46, 1-18.

Antaki, C, Finlay, WML, Walton, C. (2007b). Conversational shaping: staff-members' solicitation of talk from people with an intellectual impairment. Qualitative Heath Research, 17, 1403-414.

Bolden, G. B. (2005). Delayed and incipient actions: The discourse markers "-to" and "so" in Russian and English conversation. Unpublished doctoral dissertation, University of California, Los Angeles.

Bolden, G.B. (2006). Little Words That Matter: Discourse Markers "So" and "Oh" and the Doing of Other-Attentiveness in Social Interaction, Journal of Communication 56, $661-688$

Button, G. (1987). Moving out of closings. In G. Button and J.R.E. Lee (Eds). Talk and social organisation. Clevedon: Multilingual Matters.

Button, G (1990). On varieties of closing. In G. Psathas (Ed.) Interaction Competence. Maryland: International Institute for Ethnomethodology and Conversation Analysis and University Press of America.

Button, G. (1991). Conversation-in-a-series. In D. Boden and D.H. Zimmerman (Eds) Talk and social structure: Studies in ethnomethodology and conversation analysis. Cambridge: Polity Press

Edwards, D. (2005). Discursive Psychology. In K.L. Fitch and R.E. Sanders (Eds). Handbook of language and social interaction. Mahwah, NJ: Lawrence Erlbaum Associates 
Finlay, W M L Antaki, C. and Walton, C. (2008a). Saying no to the staff: an analysis of refusals in a home for people with severe communication difficulties, Sociology of Health and IIIness, 30, 55-75.

Finlay, WML, Walton, C and Antaki, C. (2008b). Promoting choice and control in residential services for people with learning disabilities, Disability and Society, 23.

Goodwin, C. (1995). Co-constructing meaning in conversations with an aphasic man, Research on Language and Social Interaction, 28, 233-260.

Goodwin, C. (2003). Introduction. In C. Goodwin (Ed.), Conversation and brain damage (pp. 3-20). New York: Oxford University Press.

Goodwin, C. (2003). Conversational frameworks for the accomplishment of meaning in aphasia. In C. Goodwin (Ed.). Conversation and Brain Damage (pp. 90-116). New York: Oxford University Press.

Goodwin, C. (2004). A Competent speaker who can't speak: The social life of aphasia, Journal of Linguistic Anthropology,14, 151-170.

Goodwin, C. (2006). Human sociality as mutual orientation in a rich interactive environment: Multimodal utterances and pointing in aphasia. In N.J. Enfield and S.C. Levinson (Eds.) Roots of human sociality: Culture cognition and interaction (pp. 97-125). London: Berg Publishers

Hepburn, A. \& Wiggins, S. (2007). Discursive research in practice: New approaches to psychology and interaction. New York: Cambridge University Press.

Heritage, J. \& Raymond, G. (2005). The Terms of Agreement: Indexing Epistemic Authority and Subordination in Assessment Sequences, Social Psychology Quarterly, 68, 15-38. Hopper, R. (1992) Telephone Conversation. Indianapolis: Indiana University Press 
Jefferson, G. (2004). Glossary of transcript symbols with an introduction. In G.H Lerner (Ed.). Conversation Analysis: Studies from the first generation. Amsterdam/Philadelphia: John Benjamins.

Levinson, S.C. (1983). Pragmatics. Cambridge: Cambridge University Press.

Ochs, E., Kremer-Sadlik, T., Sirota K.G., and Solomon, O. (2004). Autism and the social world: an anthropological perspective, Discourse Studies, 6, 147-183

Patterson, A. (in preparation) Managing relationality: Affiliative practices in pre-closing sequences in phone calls with young adults with learning disabilities.

Pavlidou, T (2002). Moving towards closing: Greek telephone calls between familiars, in K.K Luk and T. Pavlidou (Eds). Telephone Calls: Unity and diversity in conversational structure across languages and cultures. Amsterdam: John Benjamins.

Pomerantz, A.M. (1980). Telling my side: 'limited access' as a fishing device, Sociological Inquiry, 50, 186-198.

Sacks, H. (1992). Lectures on Conversation, Volumes I and II, G Jefferson (ed.) (2 Vols.), Oxford: Basil Blackwell

Schegloff, E.A. and Sacks, H. (1973). Opening up Closings, Semiotica, 7, pp 289-327

Schegloff, E.A. (2006). Human sociality as mutual orientation in a rich interactive environment: Multimodal utterances and pointing in aphasia. In N. Enfield and S.C. Levinson (Eds). Roots of Human Sociality pp. 70-96. London: Berg Publishers Shakespeare, P. (1998). Aspects of confused speech: A study of verbal interaction between confused and normal speakers. Mahwah, NJ: Lawrence Erlbaum Associates Solomon, O. (2004). Narrative introductions: discourse competence of children with autistic spectrum disorders, Discourse Studies, 6, 147-183. 
Wiggins, S. \& Potter, J. (2008). Discursive psychology. In C. Willig, \& W. Hollway (Eds). Handbook of qualitative research in psychology (pp. 72-89). London; Sage. 


\section{Notes}

We sometimes see 'latent accounts' - that is, items that have the potential to be turned into full accounts - as standalone items, but they are transformed into preclosings in one of the three forms noted here. Of those pre-closings with accounts $32 \%$ are initiated by an announcement; $47 \%$ are initiated by an interrogative; $21 \%$ are initiated by an imperative.

The young adult participant is 19 years of age and diagnosed as having moderate learning difficulties (IQ 35-55, based on Diagnostic and Statistical Manual of Mental Disorders, Fourth Edition, Text Revision, American Psychiatric Association, 2000, 1994 classification). Associated and contributory diagnoses relate to Autistic Spectrum Disorder (ASD) and petit mal epilepsy. We note this as it may well be of interest to psychologists concerned with this topic. Nevertheless, our concern is how Sue's identity and ability become relevant in concrete interaction between her and her family.

All parties to this corpus gave informed consent. Sue is of course a pseudonym. Particular attention was paid to explaining the research and its value in ways that 'Sue' could understand. The CTS corpus contains telephone conversations between young women, their friends and members of their family. The subset we used were between young adults and their mother and grandmother. We are indebted to Clare Jackson for sharing her data and taking time to locate and forward appropriate calls.

Such items are recurrent in the Holt corpus of mundane calls. 


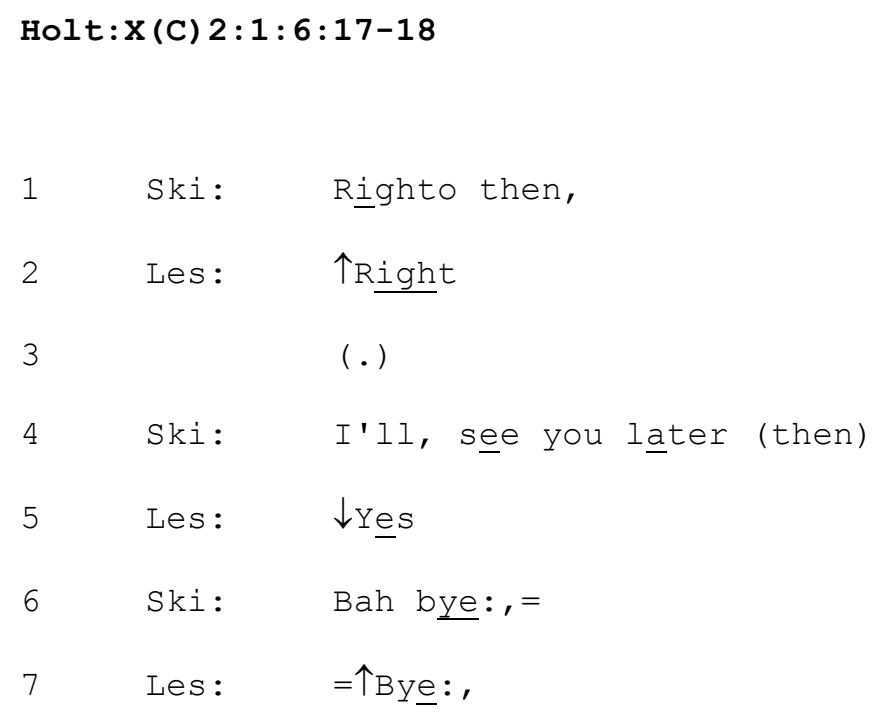

On line 1 Ski marks the resolution of previous talk and in line 4 he references a future meeting.

A search through the Holt corpus revealed that though there were occasional references to events which might imply that a call will be terminated, such items were not built as accounts for call closure. For example, in the following example from Holt, Les recycles mention of a film that has already been mentioned earlier in the call. So although it might be a relevant next activity to the call it is introduced in passing ("^by the way") rather than as a justification for closure.

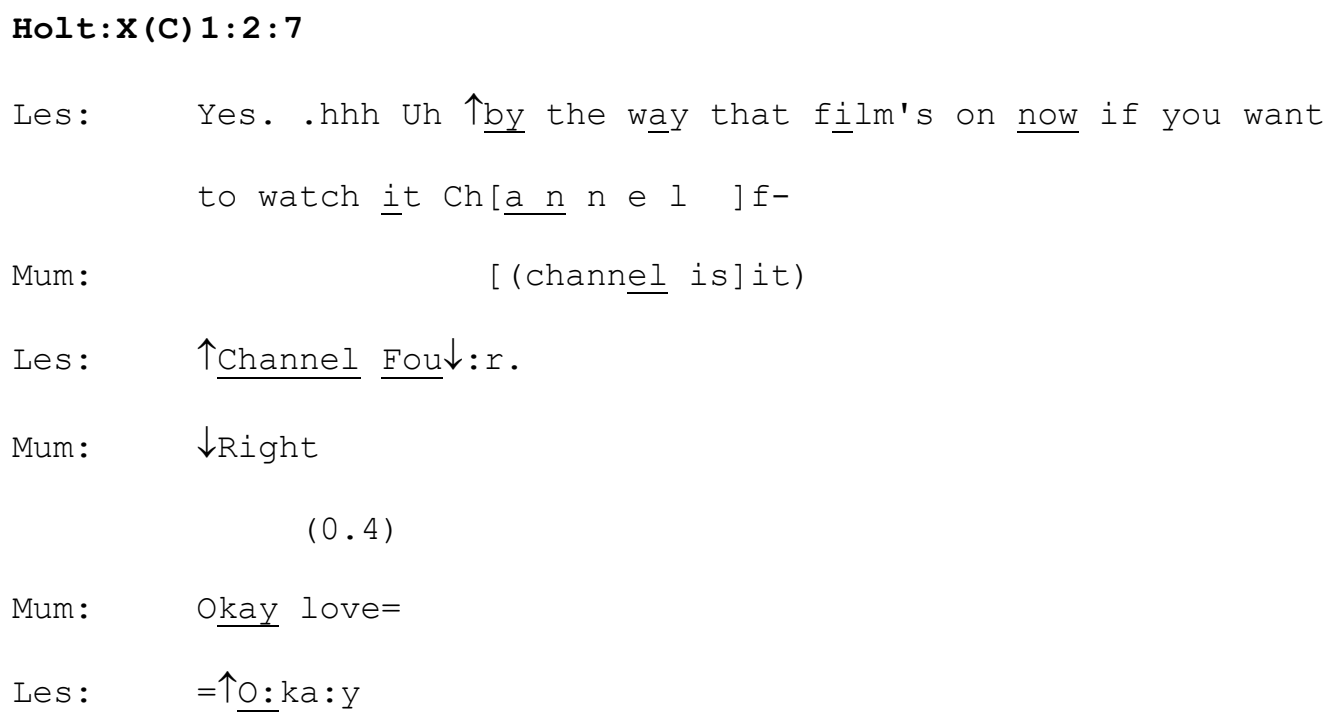




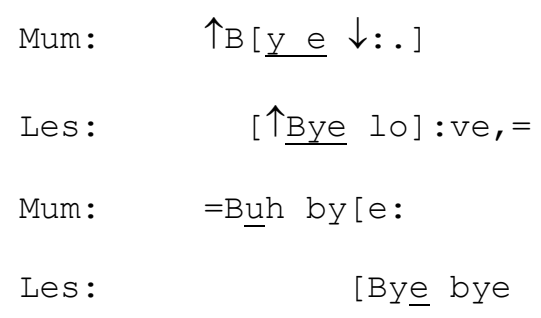

Whilst this might be viewed as a more subtle way of invoking something that could orient to the end of a call, the fact that in the APS corpus these are actively and collaboratively built into accounts is the very phenomena that we are interested in. It highlights a difference between that which is made explicit and that which is not and in turn what 'action(s)' might be being carried out by the making explicit of an account to close.

Note that in this closing format the speaker who initiates the closing constructs it, by way of the account, as for the benefit of the other. Such initiations may or may not so benefit the other. They somewhat obscure (by focusing on the other) possible benefits for the initiating speaker. However, the interrogative form allows the recipient to easily resist the closing, which regularly happens.

Note that reporting on matters that are the business of the recipient is often a complex and delicate business. For example, Pomerantz (1980) shows how reporting on something known to the recipient may be an initiating action that can 'fish' indirectly for some further information or a further action such as a party invitation. 